\title{
AVIRIS-NG HYPERSPEGTRAL DATA FOR MAPPING MANGROVE FORESTS AND THEIR HEALTH SPATIALLY: A CASE STUDY OF INDIAN SUNDARBANS
}

\author{
Kumar $\mathbf{T}^{1, *}$, Kaur $\mathbf{P}^{2}$, Chandrasekar $\mathbf{K}^{3} \&$ Bandyopadhyay $\mathbf{S}^{1}$ \\ ${ }^{1}$ Regional Remote Sensing Centre-East, National Remote Sensing Centre, Indian Space Research Organisation, BG-2, \\ Action Area-1B, New Town, Kolkata 700156, India \\ ${ }^{2}$ Department of Geography, Savitribai Phule Pune University, Ganeshkhind, Pune 411 007, India \\ ${ }^{3}$ Regional Centre, National Remote Sensing Centre, Indian Space Research Organisation, Balanagar, Hyderabad 500037 , \\ India \\ *tanumi_k@nrsc.gov.in
}

Submitted October 2019; accepted January 2020

\begin{abstract}
The present work deals with the classification of mangrove forests and determination of their health spatially using Airborne Visual Imaging Infrared Spectrometer-Next Generation data over a portion of Indian Sundarbans. The objectives were to test pixel-based classifiers and object-based approach for classification of mangroves into floristic composition classes and map the health status of the forests. Five known spectral indices were applied in Decision Tree algorithm for identifying mangrove forests, followed by creation of a mangrove mask of the study area. Spectral Angle Mapper, Support Vector Machine (SVM), and Object-Based Image Analysis classifiers were separately evaluated on the data within the mask. The overall classification accuracy was highest in SVM (99\%). A total of 10 floristic composition classes were obtained. The classes were further classified into three health classes, viz. most healthy, moderately healthy and less healthy/stressed using different vegetation indices for greenness, light-use efficiency, leaf pigments and canopy moisture contents. The methodology presented here holds good opportunity to be applied to other mangrove forests for producing mangrove health maps at finer levels.
\end{abstract}

Keywords: Airborne hyperspectral data; support vector machine; vegetation indices; decision tree; mangrove health

\section{INTRODUCTION}

Mangrove forests or "mangals" are a type of intertidal wetland ecosystems. These forests grow in harsh environmental conditions with high levels of salinity, high temperature, extreme tides, high rates of sedimentation and muddy anaerobic soils. Sundarbans is considered to be one of the world's largest blocks of mangrove ecosystem. Presently, Sundarban Biosphere Reserve has about 26 true mangrove species, 29 mangrove associates and 29 back mangrove species belonging to 60 genera and 40 species (Sundarban Biosphere Reserve 2006).

The application of hyperspectral technology may be a step closer for accurate discrimination of tropical mangrove species. The potential of hyperspectral imaging and image processing has already been demonstrated for numerous applications in vegetation structure, composition and physiology (Kumar et al. 2001). The advantage is mainly due to its ability to measure reflectance and absorption in large number of narrow and contiguous spectral bands, generally covering 400 to $2500 \mathrm{~nm}$ range of the electromagnetic spectrum. Measurements beyond the non-photosynthetic spectral range facilitate new possibilities to differentiate mangroves based on additional components, such as leaf water content and leaf chemistry in relation to ecosystem (Mc Donald 2003, Schmidt \& Skidmore 2003). Hyperspectral data allows for better separation of feature types based on their unique spectral reflectance and absorption characteristics (Held et al. 2003). These data may, therefore, improve our ability to differentiate mangroves from other terrestrial forests and then classify the forests at species-level.

Many studies have been carried out in the past few years on mangrove forests using satellite hyperspectral image data. Although, the researches included determination of health 
of the mangroves using two vegetation indices, namely, Enhanced Vegetation Index (EVI) and Structure Insensitive Pigment Index (SIPI), no details were given regarding the generated health outputs by using the two indices.

The mapping accuracy of a mangrove forest strongly depends on the classification technique adopted (Green et al. 1998). In comparison to unsupervised or supervised classification methods, Decision Tree (DT) classifier is computationally faster (Friedl \& Brodley 1997). Different vegetation/spectral indices have been computed using multispectral and hyperspectral space-borne satellite imagery for characterising the mangrove forests (e.g. Kamal et al. 2016, Kumar et al. 2019), but such investigations are insufficient in the domain of high resolution airborne hyperspectral data over Sundarbans mangroves. Moreover, there are virtually no authentic studies on the classification of Indian Sundarbans mangroves using high resolution airborne hyperspectral image data. There is lack of reports on the classification of these mangroves at species-level with accuracy assessments of the classified outputs using ground truth data. Additionally, it would be useful to determine the health of these mangrove forests/mangroves species using different vegetation indices in DT algorithm.

The objectives of the present study were to test the pixel-based classifiers and object-based approach for classification of mangroves into floristic composition classes and determine the health status of the mangroves spatially.

\section{MATERIALS AND METHODS}

\section{Study area}

The pristine mangrove habitats of Bhagabatpur island, major portions of Lothian island together with some of the fringing mangrove forests of Indian Sundarbans with adjoining agricultural and settlement areas extending between $21^{\circ} 56^{\prime}$ to $21^{\circ} 57^{\prime} \mathrm{N}$ and $88^{\circ} 22^{\prime}$ to $88^{\circ} 24^{\prime} \mathrm{E}$ was selected as the study area (Figure 1).
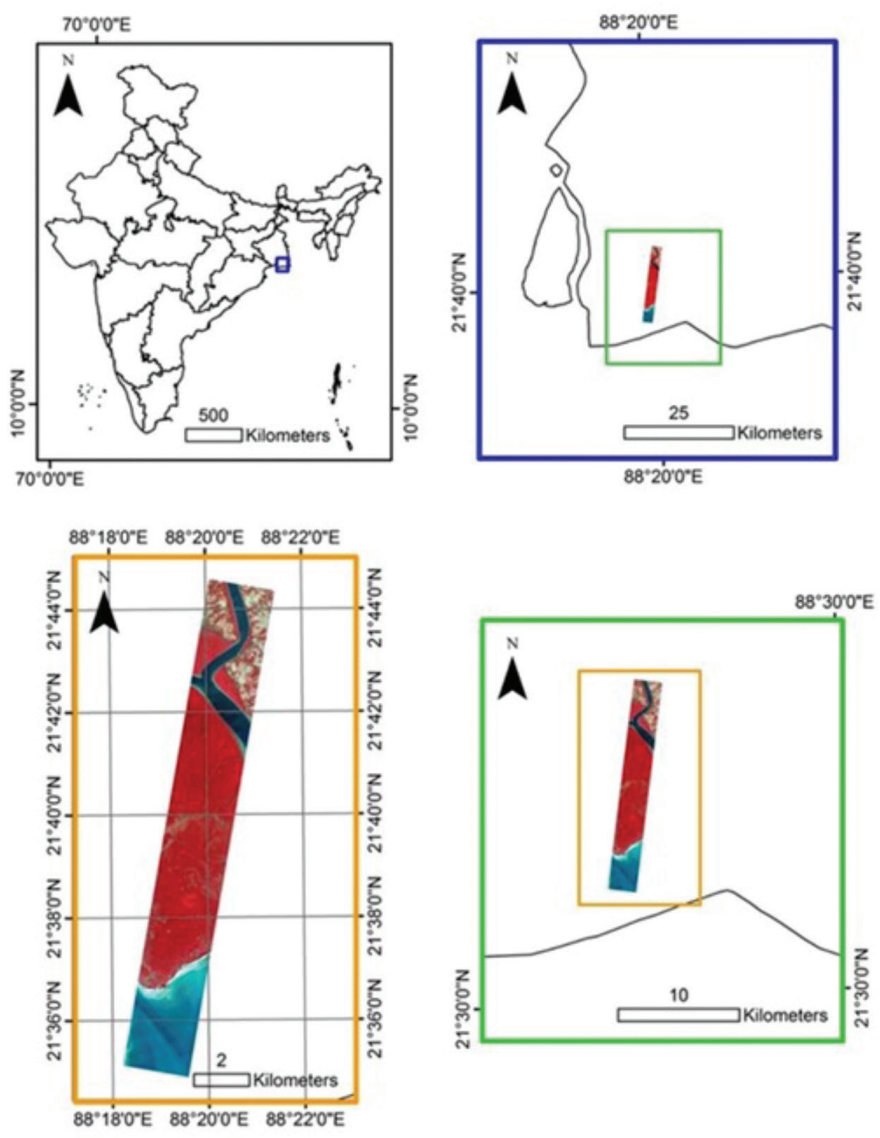

Figure 1 Index map of the study area and false colour composite of the AVIRIS-NG data 


\section{Data used}

Airborne Visible and InfraRed Imaging Spectrometer-Next Generation (AVIRIS-NG) airborne campaign data, i.e. a joint collaboration of Jet Propulsion Laboratory (JPL), NASA and Indian Space Research Organisation (ISRO), were used in the present study. There were 425 narrow continuous spectral bands in the visible and near infrared (VNIR) and shortwave infrared (SWIR) regions in the range of 376$2500 \mathrm{~nm}$ at $5 \mathrm{~nm}$ interval with high signal-tonoise ratio (SNR) with accuracy of $95 \%$ having field of view $34^{\circ}$ and instantaneous field of view of $1 \mathrm{mrad}$. The scene characteristics of AVIRISNG image over Sundarbans area are listed in Table 1.

Ground truth data regarding the geographic distribution of different mangrove species in the study area were collected along with published maps and reports on the distribution of mangrove species in the Indian part of the Sundarbans (Ajai et al. 2012, Nayak et al. 2003).

\section{METHODOLOGY}

\section{Removal of bad bands and data reduction}

All the bands were visually examined and a list of bad bands was prepared. AVIRIS-NG data had 425 bands, of which bad bands (which included no information bands, higher noise level bands and water vapour absorption bands) were removed. Reflectance values of random pixels of regions of interests (ROIs) for all the bands (excluding the bad bands) were subjected to factor analysis which attempts to identify underlying variables/factors (here bands) that explain the pattern of correlations within a set of observed variables. The method used for extraction was Principal Component Analysis (PCA) following Richards and Jia (2006). The technique adopted for rotation was Varimax method with Kaiser Normalization (SPSS 13.0, 2004). Only Eigenvalues over 1 were extracted and principal components were analysed on the basis of a correlation matrix. The selection of uncorrelated wavelengths was done using factor analysis tool in SPSS software. The bands registering correlation coefficients $\geq 0.8$ were considered for further analysis.

\section{Computation of pixel-based spectral indices}

Five known/already published spectral or vegetation indices were applied on the AVIRISNG reflectance image data (bands after data reduction). These indices are as follows:

\section{Mangrove Probability Vegetation Index (MPVI)}

MPVI (Kumar et al. 2019), a kind of spectral matching algorithm, was used to identify the image pixels that might fit in or belong to a

Table 1 Scene characteristics of the AVIRIS-NG data

\begin{tabular}{|c|c|}
\hline Dataset attribute & Attribute value \\
\hline Acquisition date & $5^{\text {th }}$ March 2016 \\
\hline North-west corner & $21^{\circ} 56^{\prime} 54.77^{\prime \prime} \mathrm{N}, 88^{\circ} 22^{\prime} 27.40^{\prime \prime} \mathrm{E}$ \\
\hline North-east corner & $21^{\circ} 57^{\prime} 19.50^{\prime \prime} \mathrm{N}, 88^{\circ} 24^{\prime} 22.40^{\prime \prime} \mathrm{E}$ \\
\hline South-west corner & $21^{\circ} 33^{\prime} 26.65^{\prime \prime} \mathrm{N}, 88^{\circ} 17^{\prime} 42.00^{\prime \prime} \mathrm{E}$ \\
\hline South-east corner & $21^{\circ} 33^{\prime} 21.66^{\prime \prime} \mathrm{N}, 88^{\circ} 19^{\prime} 24.42^{\prime \prime} \mathrm{E}$ \\
\hline Dimension & $747 \times 9167 \times 425[\mathrm{BIL}]$ \\
\hline Datum & North America 1927 \\
\hline Target path & 138 \\
\hline Projection & UTM, Zone 45 North \\
\hline Sensor type & AVIRIS-NG, PHASE 1 \\
\hline Spatial resolution & $5 \mathrm{~m}$ \\
\hline Radiometric resolution & 14 bits \\
\hline Product & L2 (atmospherically corrected) \\
\hline
\end{tabular}


particular mangrove forest type by calculating their correlation coefficients with a "certain spectrum' of mangrove forest. The MPVI was calculated as given in equation (1).

$$
\text { MPVI }=\frac{n \sum_{i=1}^{n} B_{i} b_{i}-\sum_{i=1}^{n} B_{i} \sum_{i=1}^{n} b_{i}}{\sqrt{n \sum_{i=1}^{n} B_{i}^{2}-\left(\sum_{i=1}^{n} B_{i}\right)^{2}} \sqrt{n \sum_{i=1}^{n} b_{i}^{2}-\left(\sum_{i=1}^{n} b_{i}\right)^{2}}}
$$

where, $\mathrm{n}=$ total number of bands in the image (270 in the present study), $B_{i}=$ reflectance value at band i for a pixel of the reflectance image, and $b_{i}=$ reflectance value at band i for a certain spectrum of mangrove forest. The average spectrum of these pixels (average spectrum of ROIs taken over known mangrove forest locations on the reflectance image) was computed as the certain spectrum of mangrove forest. MPVI was computed using the band math tool in ENVI.

\section{Normalized Difference Wetland Vegetation Index (NDWVI)}

The spectral reflectance of mangrove forests is lower than that of terrestrial vegetation at the SWIR region and, thus, NDWVI was used. Two bands were considered, viz. one in the SWIR region and the other in the green region to enhance the discrimination of mangrove forests and terrestrial vegetation (Kumar et al. 2019). NDWVI was computed using the band math tool in ENVI. In the present study, reflectance (R) values at $2204 \mathrm{~nm}$ and $556 \mathrm{~nm}$ were used as given in equation (2).

$$
\mathrm{NDWVI}=\frac{\mathbf{R}_{2204}-\mathbf{R}_{556}}{\mathbf{R}_{2204}+\mathbf{R}_{556}}
$$

\section{Shortwave Infrared Absorption Depth (SIAD)}

This index (Kumar et al. 2019) was used to highlight the water absorption features of mangrove forests. In the present study, reflectance value at $1578 \mathrm{~nm}$ was used. Before the calculation of absorption depth, the continuum-removed reflectance was calculated. The used formula for SIAD calculation (equation 3) was as follows:

$$
\mathrm{SIAD}=1-\mathrm{CR}_{1578}
$$

where, $\mathrm{CR}_{1578}=$ continuum-removed value at $1578 \mathrm{~nm}$. SIAD was computed using the band math tool in ENVI.

\section{Normalized Difference Infrared Index (NDII)}

The NDII is a reflectance measurement that is sensitive to change in water content of plant canopies. The value of this index ranges from -1 to 1 (Hardisky et al. 1983, Jackson et al. 2004). The common range for green vegetation is 0.02 to 0.6 . NDII in the present study was defined by equation (4).

$$
\mathrm{NDII}=\frac{\mathbf{R}_{819}-\mathbf{R}_{1649}}{\mathbf{R}_{819}+\mathbf{R}_{1649}}
$$

where, $\mathbf{R}_{819}$ and $\mathrm{R}_{1649}=$ reflectance values of $819 \mathrm{~nm}$ and $1649 \mathrm{~nm}$ respectively. NDII was computed using the band math tool in ENVI.

\section{Atmospherically Resistant Vegetation Index (ARVI)}

The ARVI is an improvement to the Normalized Difference Vegetation Index (NDVI) that is relatively unaffected by atmospheric constituents (e.g. aerosol). It is most useful in tropical regions. The common range of ARVI for green vegetation is 0.2 to 0.8 . ARVI is defined by equation (5) (Kaufman \& Tanre 1996).

$$
A R V I=\frac{\left(R_{\text {NIR }}-2\right)\left(R_{\text {RED }}-R_{\text {BLUE }}\right)}{\left(R_{\text {NIR }}+2\right)\left(R_{\text {RED }}-R_{\text {BLUE }}\right)}
$$

where, $R_{B L U E}, R_{R E D}$ and $R_{N I R}=$ reflectance values of the wavelengths in the blue, red and NIR regions of the spectrum respectively. ARVI was computed using the ARVI option of the vegetation index calculator under vegetation analysis tool in ENVI.

\section{Identification and extraction of mangrove forests/mangroves}

Decision Tree method was used for identification of mangrove vegetation. The above mentioned spectral/vegetation indices (MPVI, NDWVI, SIAD, NDII and ARVI) were used as inputs in the DT classifier. Figure 2 illustrates the decision rules for identifying mangrove forests using 
DT and the reflectance image. The images of the indices were stacked for highlighting the mangrove forests and the DT rules for the identification of the forests were obtained after thresholding to cover all mangrove pixels. A mangrove mask was built using the classified output of DT.

\section{Classification}

In this study, three kinds of classifiers, viz. two types of supervised full-pixel classifiers, namely, Spectral Angle Mapper (SAM) and Support Vector Machine (SVM) and object-based classifier (Object-Based Image Analysis (OBIA)) were used. Known locations of definite floristic composition were used as training site pixels. Minimum noise fraction transformation (MNF) was carried out in ENVI and the first $10 \mathrm{MNF}$ bands were used for classification.

\section{Spectral Angle Mapper}

A physically-based spectral classifier, namely, SAM utilises n-D angle to match pixels to reference spectra. Endmembers were retrieved from specified ROIs. The acceptable angle set was 0.1 rad as ENVI does not classify pixels with an angle larger than this value.

\section{Support Vector Machine}

SVM provides high-quality classification results from intricate and noisy data (Chang \& Lin 2011). The SVM parameters set were kernel type (sigmoid), bias in kernel function (1), gamma in kernel function (0.005), penalty parameter (100), pyramid level (0) and classification probability threshold $(0)$.

\section{Object-Based Image Classification (OBIA)}

The algorithm of multi-resolution segmentation was employed, followed by supervised classification. The parameters used were: classification method-nearest neighbourhood, domain-pixel level, shape-0.1, compactness- 0.5 and scale parameter-1.5. The image was classified using the first $10 \mathrm{MNF}$ bands. eCognition software was used for OBIA.

\section{Classification accuracy comparison}

This was done using post classification confusion matrix with ground truth ROIs. A comparison was drawn amongst the classified images of SAM, SVM and object-based image classification.

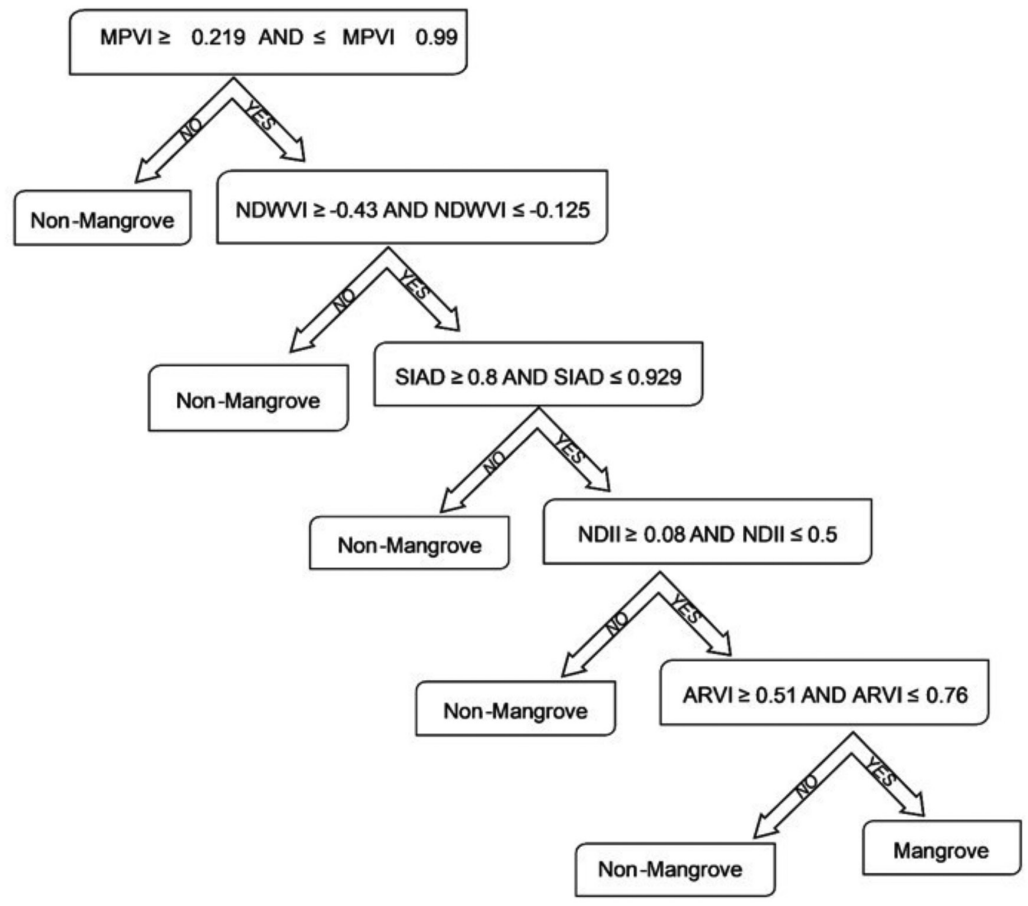

Figure 2 Rules for identifying mangrove forests of the study area using decision tree 


\section{Vegetation indices for forest health determination}

Six vegetation indices were computed for health determination of mangrove communities/ species/classes and these were as follows:

\section{Enhanced Vegetation Index (EVI)}

This index was developed to improve the NDVI by optimising the vegetation signal in Leaf Area Index (LAI) regions. It uses the blue reflectance region to correct for soil background signals and to reduce atmospheric influences, including aerosol scattering. It is most useful in LAI regions where the NDVI may saturate (Huete et al. 2002).

$$
\mathrm{EVI}=2.5 \times \frac{\left(\mathrm{R}_{\mathrm{NIR}}-\mathrm{R}_{\mathrm{RED}}\right)}{\left(\mathrm{R}_{\mathrm{NIR}}+6 \times \mathrm{R}_{\mathrm{RED}}-7.5 \times \mathrm{R}_{\mathrm{BLUE}}+1\right)}
$$

\section{Vogelmann Red Edge Index 1 (VOG1)}

This index is a narrowband reflectance measurement that is sensitive to the combined effects of foliage chlorophyll concentration, canopy leaf area, and water content (Vogelmann et al. 1993). This vegetation index (equation 7) was calculated using band math tool in ENVI.

$$
\text { VOG1 }=\frac{\mathbf{R}_{740}}{\mathbf{R}_{720}}
$$

\section{Photochemical Reflectance Index (PRI)}

This index is a reflectance measurement that is sensitive to changes in carotenoid pigments (particularly xanthophyll pigments) in live foliage. Carotenoid pigments are indicative of photosynthetic light-use efficiency, or the rate of carbon dioxide uptake by foliage per unit energy absorbed. The value of this index ranges from -1 to 1 . The common range for green vegetation is -0.2 to 0.2 . This vegetation index (equation 8 ) was calculated using band math tool in ENVI.

$$
\mathrm{PRI}=\frac{\mathrm{R}_{531}-\mathbf{R}_{570}}{\mathrm{R}_{531}+\mathrm{R}_{570}}
$$

Carotenoid Reflectance Index 1 (CRI1)

Carotenoids function in light absorption processes in plants, as well as in protecting plants from the harmful effects of too much light. Weakening vegetation contains higher concentrations of carotenoids, so this index is one measure of stressed vegetation. Higher CRI1 values mean greater carotenoid concentration relative to chlorophyll. The value of this index ranges from 0 to more than 15 . The common range for green vegetation is 1 to 12 . This index uses reflectance measurements in the visible spectrum to take advantage of the absorption signatures of stress-related pigments (Gitelson 2002). This vegetation index (equation 9) was calculated using band math tool in ENVI.

$$
\mathrm{CRI} 1=\frac{1}{\mathrm{R}_{510}}-\frac{1}{\mathrm{R}_{550}}
$$

\section{Modified Chlorophyll Absorption Ratio Index (MCARI)}

MCARI is one of several chlorophyll absorption ratio indices that indicate the relative abundance of chlorophyll. The CARI index was simplified to minimise the combined effects of soil and nonphotosynthetic surfaces (equation 10) (Daughtry 2000).

$$
\begin{aligned}
& \text { MCARI }= \\
& \quad\left[\left(\mathrm{R}_{700}-\mathrm{R}_{670}\right)-0.2\left(\mathrm{R}_{700}-\mathrm{R}_{550}\right)\right]\left(\frac{\mathrm{R}_{700}}{\mathbf{R}_{670}}\right)
\end{aligned}
$$

NDII was calculated as above (equation 4) while the ranges of the six vegetation indices (Table 2) were used in DT algorithm (Figure 3) to obtain the health classes (most healthy, moderately healthy and less healthy/stressed) for the mangrove forests.

\section{RESULTS AND DISCUSSION}

\section{Data reduction}

After removing the bad bands, 306 bands remained. The dimensionality of the data (306 bands) was determined to be 4 . Table 3 shows 
Table 2 Range of values of the vegetation indices for identification of mangrove health

\begin{tabular}{ll}
\hline Vegetation index & Range of values \\
\hline EVI & 0.15 to 0.69 \\
NDII & 0.057 to 0.450 \\
PRI & -0.024 to 0.026 \\
CRI1 & 0.210 to 2.11 \\
VOG1 & 1.118 to 1.582 \\
MCARI & 0.012 to 0.086 \\
\hline
\end{tabular}

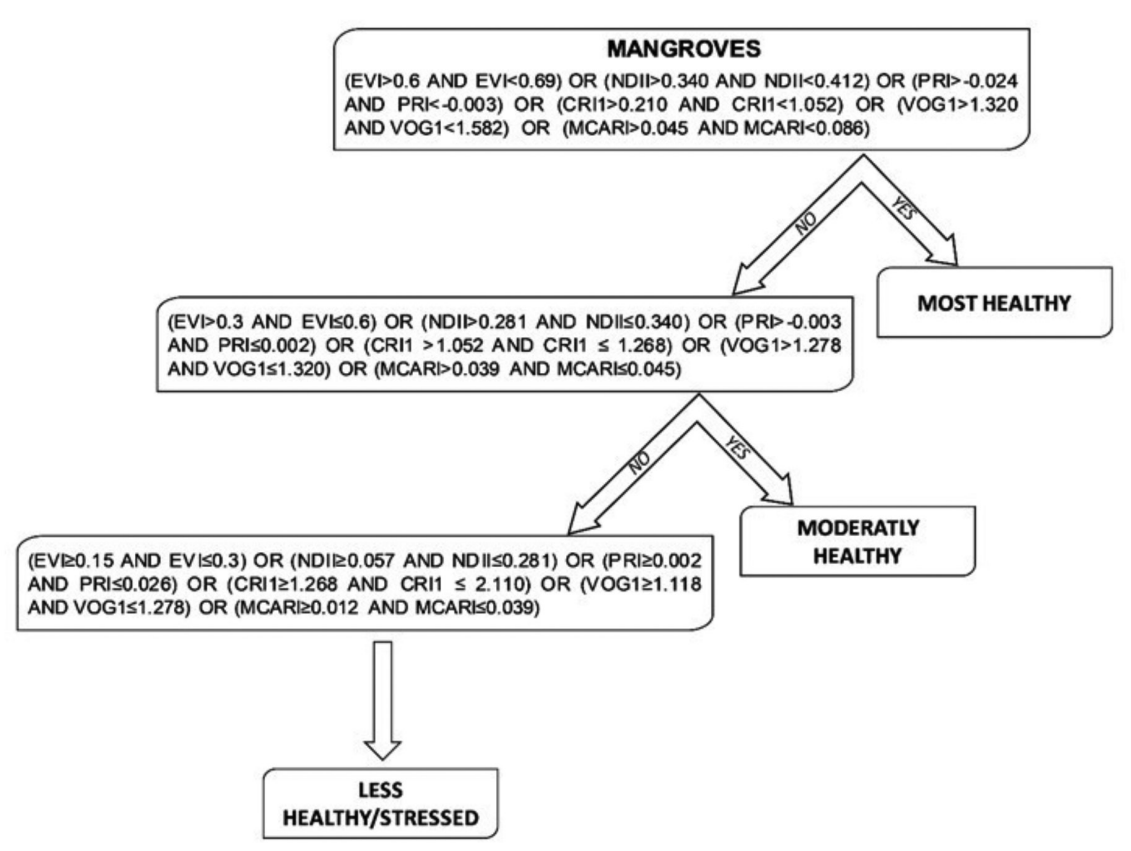

Figure 3 Rules for identifying health of the mangroves using decision tree

Table 3 Total variance explained

\begin{tabular}{|c|c|c|c|c|c|c|}
\hline \multicolumn{7}{|c|}{ Total variance explained } \\
\hline \multirow[t]{2}{*}{$\mathrm{PC}$} & \multicolumn{3}{|c|}{ Initial Eigenvalues } & \multicolumn{3}{|c|}{ Rotation sums of square loadings } \\
\hline & Total & $\%$ of variance & Cumulative $\%$ & Total & $\%$ of variance & Cumulative $\%$ \\
\hline 1 & 205.25 & 67.07 & 67.07 & 156.62 & 51.18 & 51.18 \\
\hline 2 & 92.19 & 30.12 & 97.20 & 134.73 & 44.03 & 95.21 \\
\hline 3 & 6.14 & 2.00 & 99.21 & 11.85 & 3.87 & 99.08 \\
\hline 4 & 1.25 & 0.40 & 99.62 & 1.63 & 0.53 & 99.62 \\
\hline
\end{tabular}

$\mathrm{PC}=$ principal component 


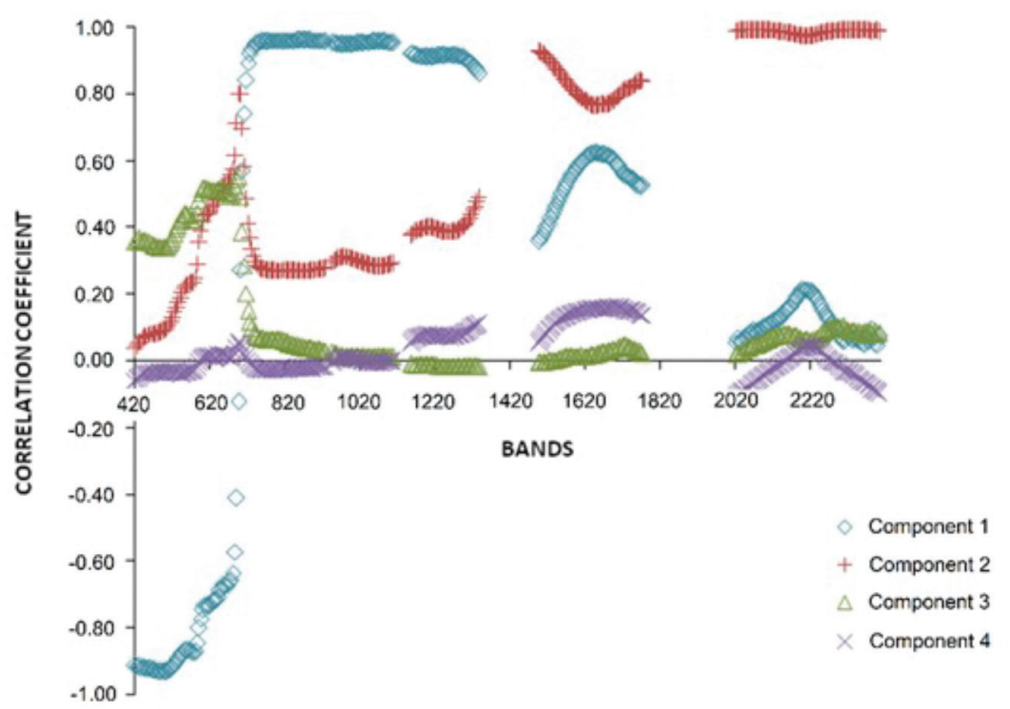

Figure 4 Rotation component matrix of 306 bands and corresponding correlation coefficients for the four principal components

the total variance explained. The factor loadings and the rotation component matrix of 306 bands and corresponding correlation coefficients for four principal components (PCs) are depicted in Figure 4. A total of 270 bands were obtained after data reduction.

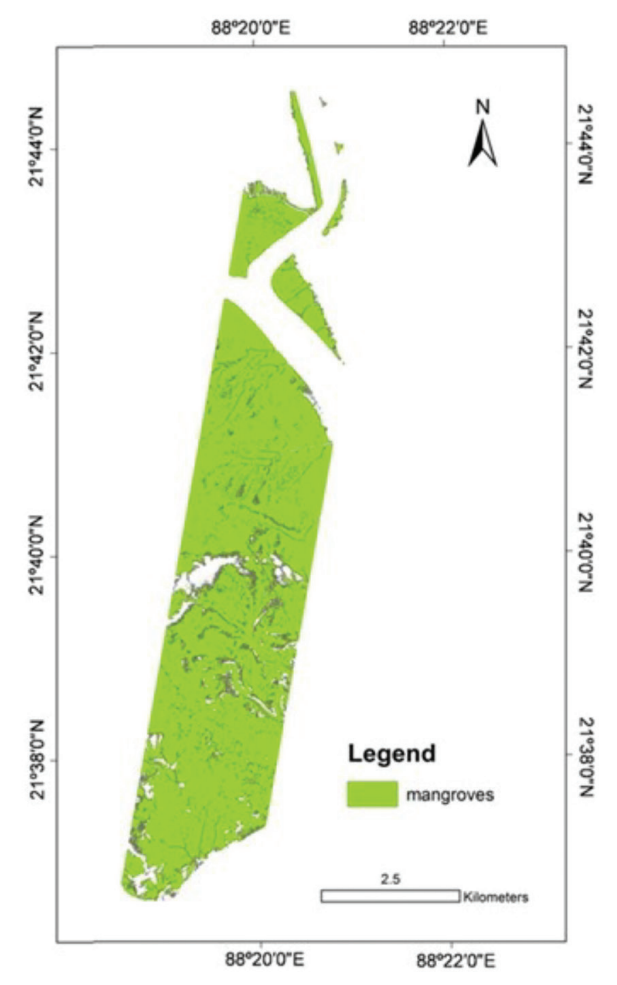

Figure 5 Decision tree output exhibiting the mangroves in the study area

\section{Identification and Extraction of Mangrove Forests/Mangroves}

The DT output exhibited the mangrove forests/ mangroves in the study area. A mask was built with the DT classified output for extraction of the mangroves (Figure 5).

\section{Classification}

A total of 10 floristic classes (including beach vegetation) were used as training sites for classification. Classified images over the mangrove forests/mangroves are shown in Figure 6.

The mangrove classes, which were characterised by the following communities/ species/zonations were: (1) Excoecaria agallochathis class was composed of pure, homogeneous and dense stands of Excoecaria agallocha; (2) Avicennia alba-this zone was composed of pure, homogeneous and dense stands of $A$. alba; (3) Avicennia marina-A. marina was the most dominant species in this class. Other mangroves that were also present were A. alba, Avicennia officinalis, Aegiceras corniculatum, Ceriops species, Bruguiera species, E. agallocha, Acanthus ilicifolius, Derris species, etc; (4) Aegialitis rotundifolia - this was composed of pure stands of $A$. rotundifolia; (5) Aegialitis-Excoecaria mixed-this community was an association of $A$. rotundifolia and $E$. agallocha and a mixture of both the species; (6) PhoenixAvicennia-Excoecaria mixed-this community 

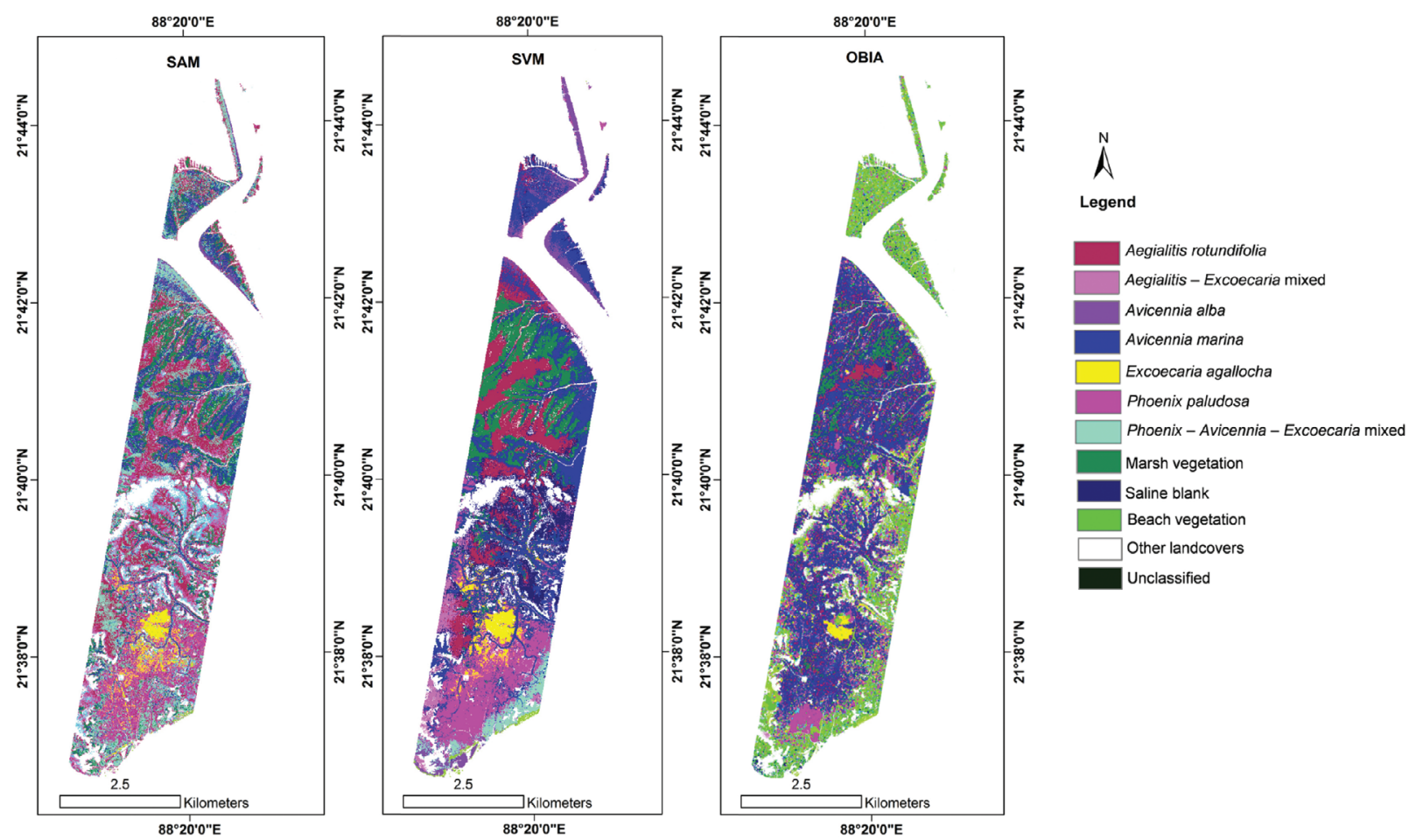

Figure 6 Spectral Angle Mapper, Support Vector Machine and object-based image classified outputs over mangrove forests

was an association of Phoenix, Avicennia sp. and E. agallocha; (7) marsh vegetation-this was characterised by Suaeda sp., Sesuvium sp., Salicornia brachiata, Acanthus ilicifolius and Avicennia marina (stunted growth); (8) Phoenix paludosa-it was composed of pure stands of P. paludosa; (9) saline blank- this class formed as a result of increase in salinity due to increase in elevation, probably because of deposition. Sparse and much stunted Avicennia sp. trees occurred in the saline blank zone.

Classification accuracy using $10 \mathrm{MNF}$ bands showed that SVM classifier provided the best results (overall accuracy $=99 \%$, Kappa coefficient $(K)=$ 0.99; Table 4), followed by SAM $(70 \%, \mathrm{~K}=0.64$; Table 5) and lastly by OBIA $(67 \%, \mathrm{~K}=0.61$; Table 6). In the classified output of SAM there were some black pixels that were unclassified. The SVM classified image showed that A. marina dominated the study area (Figure 7). Moreover, nine mangrove floristic composition classes were obtained (not including beach vegetation), of which four were at species-level (Aegialitis rotundifolia, A. alba, E. agallocha and $P$. paludosa), three were at community-level (A. marina, Aegialitis-Excoecaria mixed, Phoenix-AvicenniaExcoecaria mixed) and the remaining classes were at broad eco-morphological zonation-level (marsh vegetation and saline blank). Based on both the spatial and radiometric resolutions of EO-1 Hyperion data, Kumar et al. (2019) classified the mangroves of Lothian island into seven classes, of which only one was at specieslevel, while the rest were at community-level (besides the marsh vegetation and saline blank classes).

\section{Computation of vegetation indices for determination of forest health}

AVIRIS-NG data were used to determine the biochemical and biophysical parameters of mangrove communities and species to detect the most healthy, moderately health and less healthy or stressed mangroves. EVI and VOG1 were used to determine greenness while NDII gave moisture status of mangrove canopy. PRI was the representation for light-use efficiency of species and communities. CRI1 and MCARI showed the status of pigment contents in the leaves. Additionally, VOG1 and CRI1 measured stress in vegetation. Figure 8 shows the images for the computed indices over the mangrove forests. Cao et al. (2018) used PRI as one of the hyperspectral 


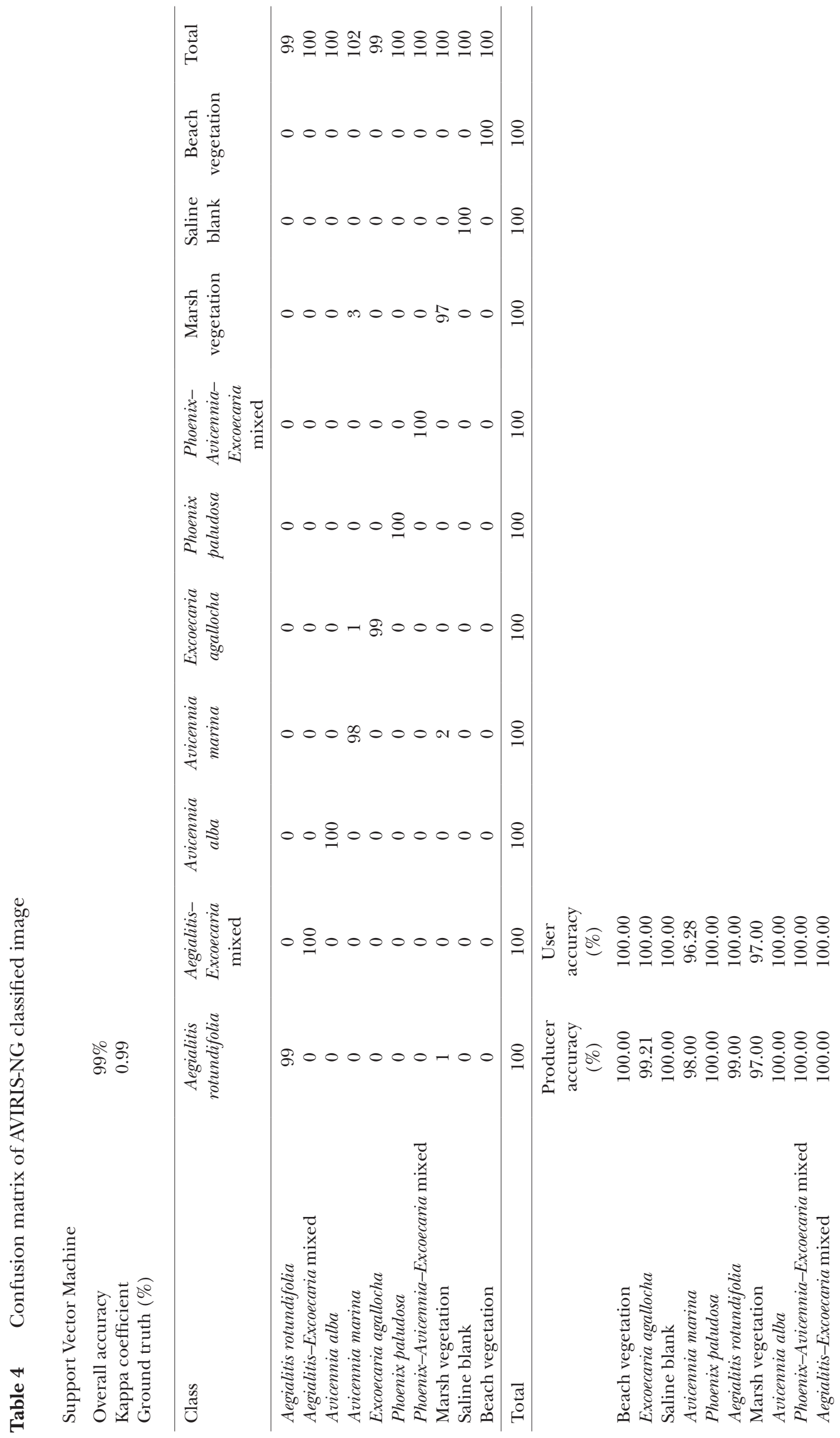




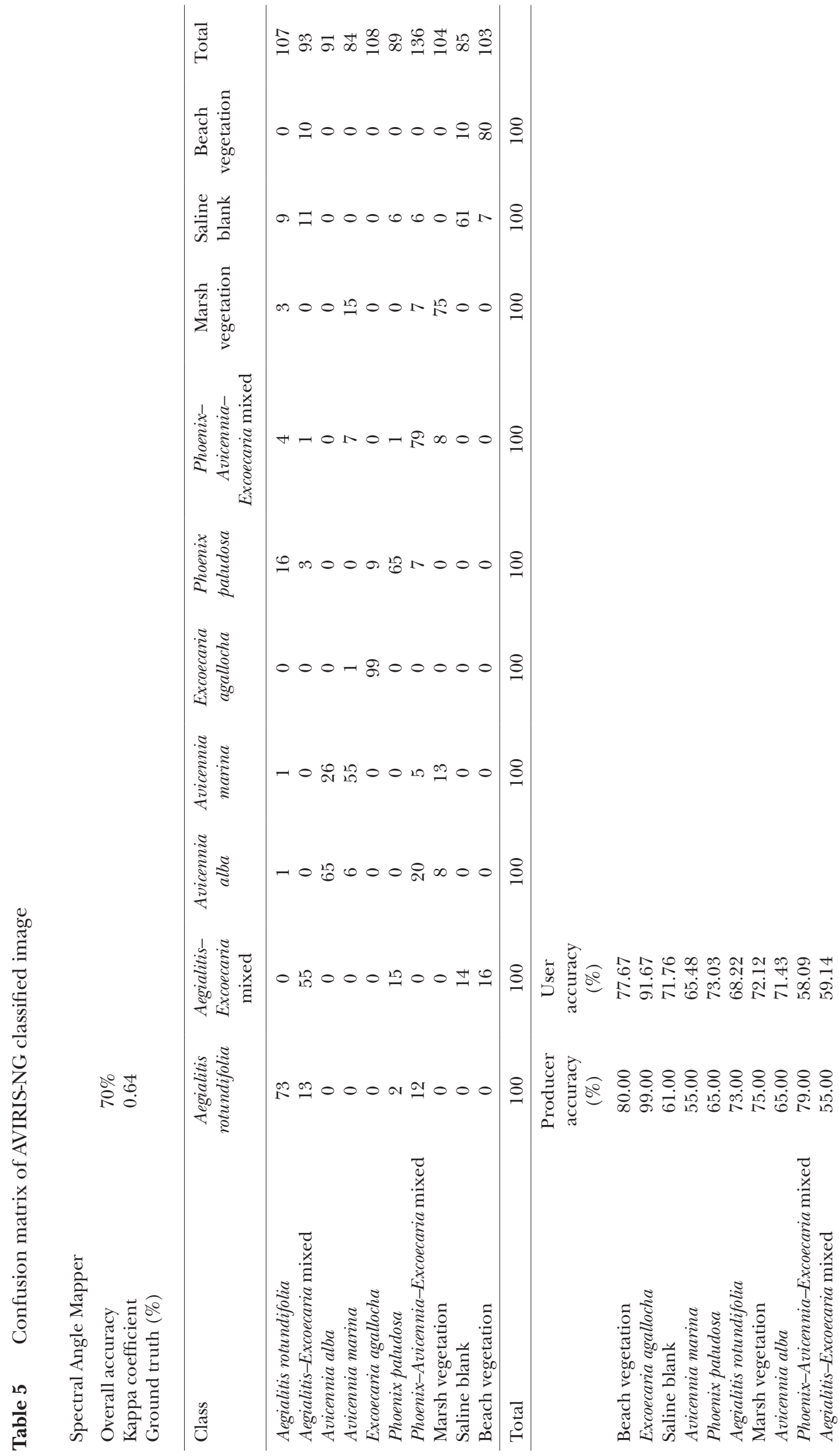




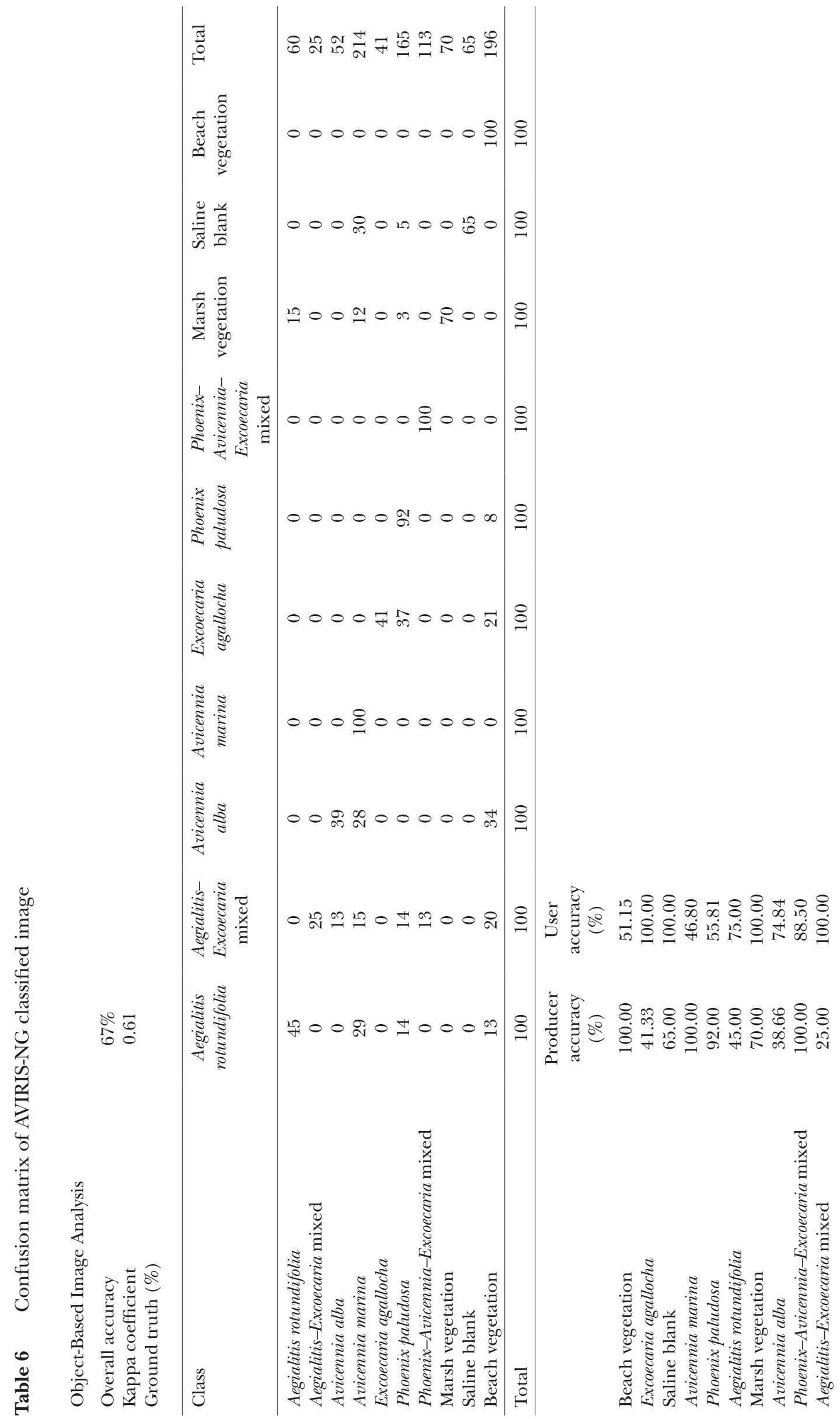




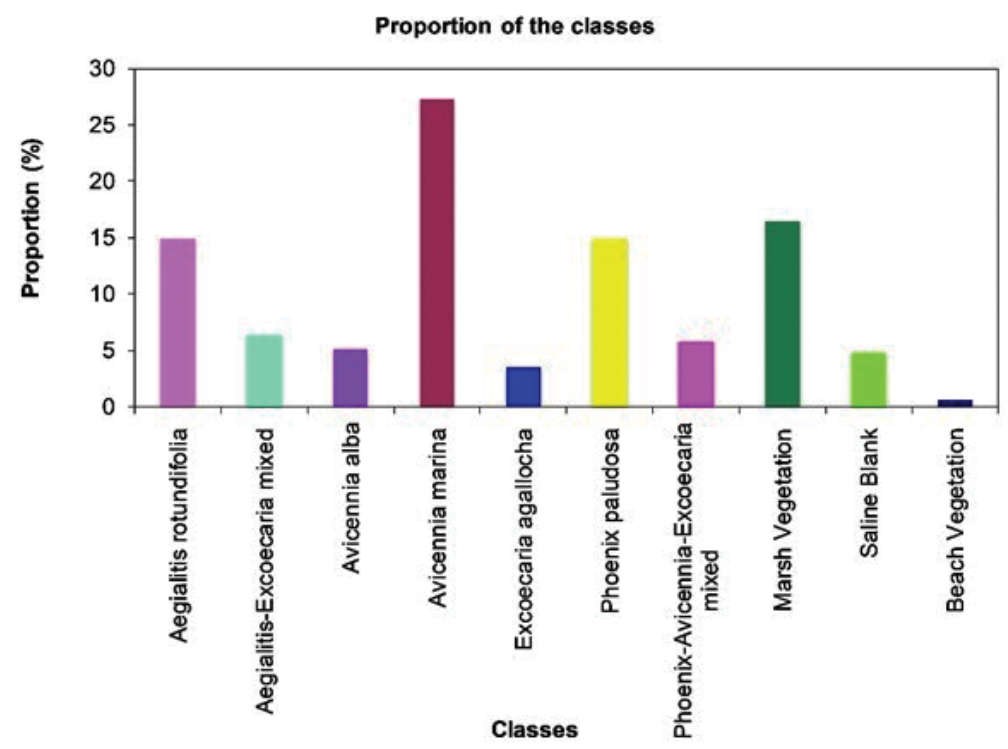

Figure 7 Proportion of different classes in the Support Vector Machine classified output
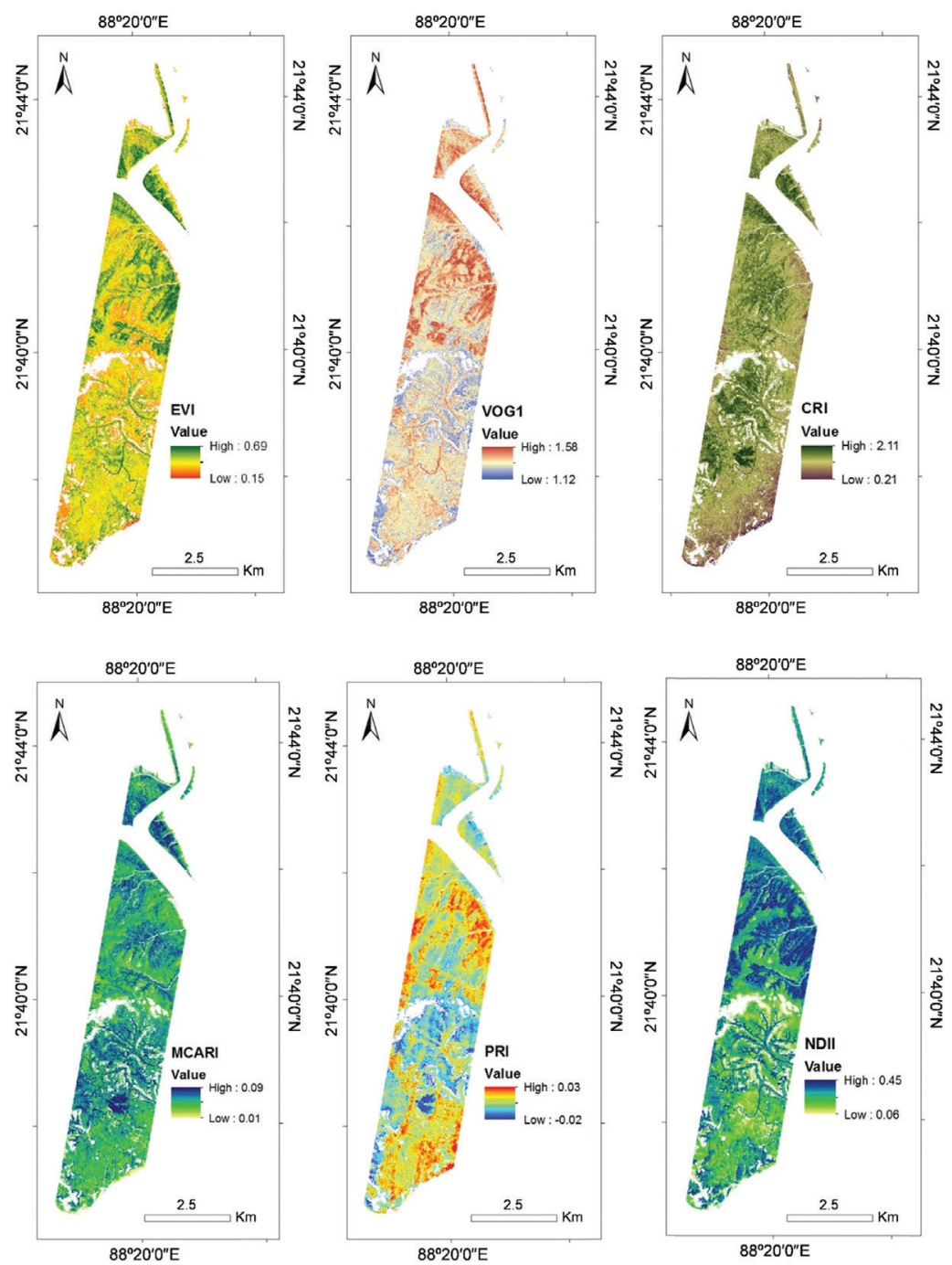

Figure 8 Outputs for the vegetation indices over mangroves 
vegetation indices in addition to other indices together with spectral and textural features to classify the mangroves at species-level in Qi'ao island, China using unmanned aerial vehicle hyperspectral images. However, they did not address the health of the mangroves in their work.

\section{Determination of health of mangrove forests/mangroves}

Six vegetation indices (EVI, NDII, PRI, CRI1, VOG1 and MCARI) were used as inputs in the DT classifier. The DT rules for the identification of the healthiness of mangrove communities and species were obtained after thresholding. The ranges of values for each of the vegetation indices have been tabulated in the methodology section. Figure 9 shows the DT output for the health classes in the study area. The result of DT algorithm indicated that the proposed indices could appreciably detect the health of the mangroves spatially. The proportions of the most healthy (healthiest) and less healthy or stressed mangroves were around 59 and $11 \%$ respectively. Figure 10 depicts the proportion

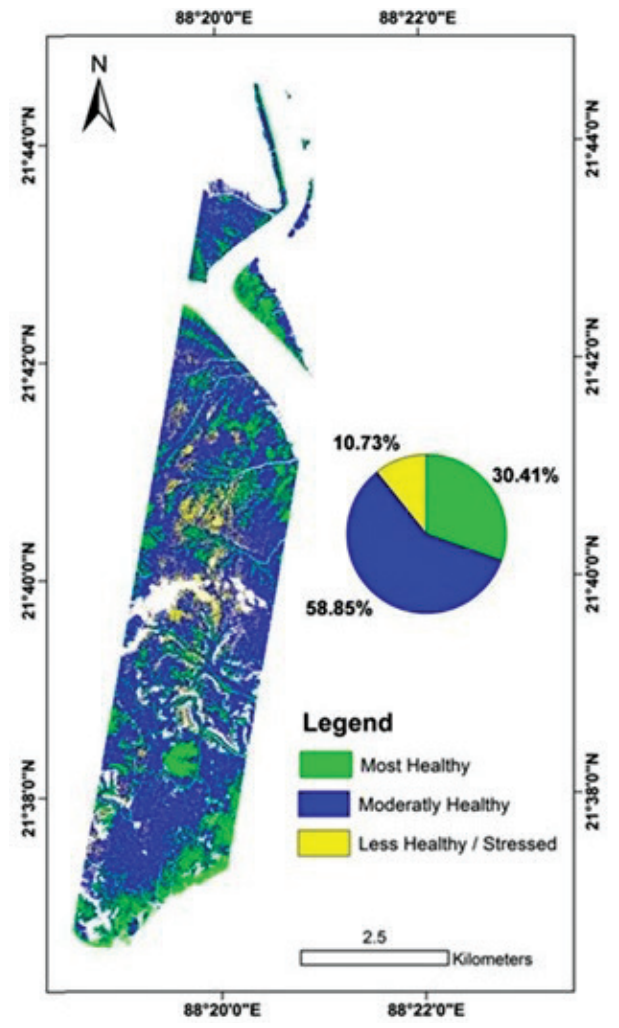

Figure 9 Mangrove health classes and their proportions in the study area
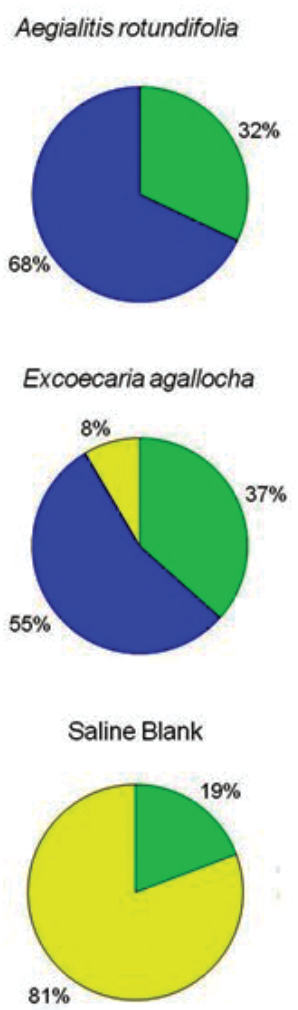
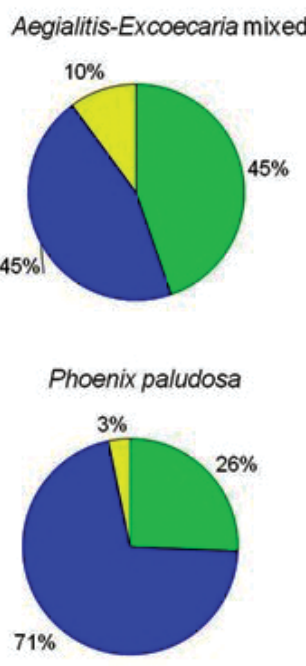

Beach Vegetation

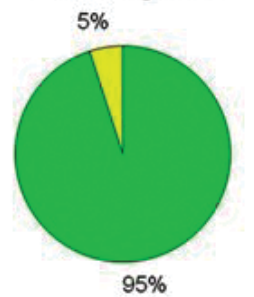

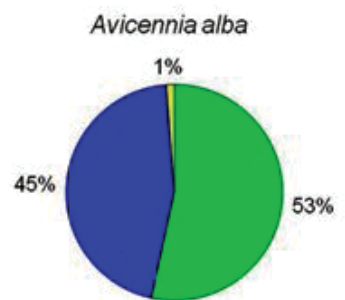

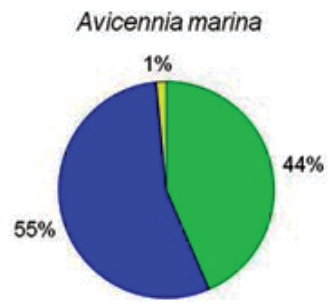

Phoenix-Avicennia-Excoecaria mixed
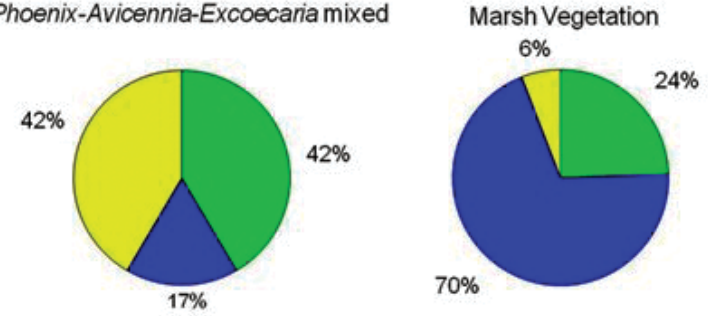

口MOST HEALTHY

"MODERATLYHEALTHY

口LESS HEALTHYISTRESSED

Figure 10 Proportion of healthiness for the different classes 
of the health status for each of the mangrove classes (including beach vegetation) obtained in case of SVM. Phoenix paludosa recorded the highest percentage of healthy mangroves. Both A. marina and A. alba were found to be the least stressed classes, while saline blank was found to be the most stressed class.

\section{CONGLUSIONS}

The present work showed that SVM outperformed the other two classifiers in terms of overall classification accuracy. Of the 10 classes, four classes (E. agallocha, A. alba, A. rotundifolia and P. paludosa) could be segregated at species-level, while the remaining classes were classified at community or zonation level. The methodology presented in this paper is being extended for other islands and localities of Indian Sundarbans and holds good opportunity to be applied to other mangrove forests for producing mangrove health maps using high resolution hyperspectral image data.

\section{ACKNOWLEDGEMENTS}

The authors are grateful to the Director, National Remote Sensing Centre (NRSC) and Chief General Manager, Regional Centres, ISRO for their support in carrying out this work. The authors express their sincere gratitude to the Director, Space Applications Centre (SAC) and Project Director (AVIRIS-NG), SAC for making the image datasets available to NRSC. The authors are grateful to Principal Chief Conservator of Forests, Director, Sundarban Biosphere Reserve and other forest officials in West Bengal Forest Department for granting permission for field data collection in the forests.

\section{REFERENCES}

Ajai, Nayak S, Tamilarasan V et al. 2012. Coastal Zones of India. Space Applications Centre, Indian Space Research Organisation, Ahmedabad.

Cao J, Leng W, Liu K, Liu L, He Z \& Zhu Y. Object-based mangrove species classification using unmanned aerial vehicle hyperspectral images and digital surface models. Remote Sensing 10: 89. https://doi. org $/ 10.3390 / \mathrm{rs} 10010089$.

Chang CC \& Lin CJ. 2011. LIBSVM: a library for support vector machines. http://www.csie.ntu.edu.tw/cjlin/.

Daughtry CST. 2000. Estimating corn leaf chlorophyll concentration from leaf and canopy reflectance. Remote Sensing of Environment 74: 229-239.
Friedl MA \& Brodley C. 1997. Decision tree classification of landcover from remotely sensed data. Remote Sensing of Environment 61: 399-409.

Gitelson AA. 2002. Assessing carotenoid content in plant leaves with reflectance spectroscopy. Photochemistry and Photobiology 75: 272-281.

Green EP, Clark CD, Mumby PJ, Edwards AJ \& Ellis AC. 1998. Remote sensing techniques for mangrove mapping. International Journal of Remote Sensing 19: 935-956.

Hardisky MA, Klemas V \& SMART RM. 1983. The influence of soil salinity, growth form, and leaf moisture on the spectral reflectance of Spartina alterniflora canopies. Photogrammetric Engineering and Remote Sensing 49: 77-83.

Held A, Ticehurst C, Lymburner L \& Williams N. 2003. High Resolution mapping of tropical mangrove ecosystems using hyperspectral and radar remote sensing. International Journal of Remote Sensing 24: 2739-2759.

Huete A, Didan K, Miura T, Rodriguez EP, Gao X \& Ferreira. 2002. Overview of the radiometric and biophysical performance of the MODIS vegetation indices. Remote Sensing of Environment 83: 195-213.

Jackson TL, Chen D, Cosh M et AL. 2004. Vegetation water content mapping using Landsat data derived Normalized Different Water Index for corn and soyabeans. Remote Sensing of Environment 92: 475-482.

Kamal M, Phinn S \& Johansen K. 2016. Assessment of multiresolution image data for mangrove leaf area index mapping. Remote Sensing of Environment 176: 242-254.

KAUfMAN YJ \& TANRE D. 1996. Strategy for direct and indirect methods for correcting the aerosol effect on remote sensing: from AVHRR to EOS-MODIS. Remote Sensing of Environment 55: 65-79.

Kumar L, Schmidt KS, Durry S \& Skidmore AK. 2001. Imaging spectrometry and vegetation science. Pp 111-155 in Van De Meer F \& De Jong SM (eds.) Imaging Spectrometry. Kluwer Academic Press, Dordrecht.

Kumar T, Mandal A, Dutta D, Nagaraja R \& Dadhwal VK. 2019. Discrimination and classification of mangrove forests using EO-1 Hyperion data: a case study of Indian Sundarbans. Geocarto International 34: 415-442.

Mc Donald MS. 2003. Photobiology of Higher Plants. John Wiley and Sons Ltd., Chichester.

Nayak SR, Bahuguna A, Shah DG et al. 2003. Community Zonation of Selected Mangrove Habitats Using Satellite Data. SAC/RESIPA/MWRG/MSCED/ SN/17/2003. Marine and Water Resource Group, Space Application Center, Indian Space Research Organisation, Ahmedabad.

Richards JA \& Jia X. 2006. Remote Sensing Digital Image Analysis: an Introduction. Springer-Verlag, Berlin Heidelberg.

Schmidt KS \& SkIDMORE AK. 2003. Spectral discrimination of vegetation types in a coastal wetland. Remote Sensing of Environment 85: 92-108.

Sundarban Biosphere Reserve. 2006. The Flora. http://www. sundarbanbiosphere.org/html_files/flora.htm.

Vogelmann JE, Rock BN \& Moss DM. 1993. Red edge spectral measurements from sugar maple leaves. International Journal of Remote Sensing 14: 1563-1575. 